Journal of Social and Development Sciences

Vol. 3, No. 9, pp. 313-321, Sep 2012 (ISSN 2221-1152)

\title{
Estimating the Effect of Climatic Variables and Crop Area on Maize Yield in Ghana
}

\author{
*Henry De-Graft Acquah, Clement Kweku Kyei \\ University of Cape Coast, Cape Coast Ghana \\ *dr.henrydegraft@gmail.com
}

\begin{abstract}
Climate change tends to have negative effects on crop yield through its influence on crop production. Understanding the relationship between climatic variables, crop area and crop yield will facilitate development of appropriate policies to cope with climate change. This study therefore examines the effects of climatic variables and crop area on maize yield in Ghana based on regression model using historical data (1970-2010). Linear and Non-linear regression model specifications of the production function were employed in the study. The study found that growing season temperature trend is significantly increasing by $0.03^{\circ} \mathrm{C}$ yearly whereas growing season rainfall trend is insignificantly increasing by $0.25 \mathrm{~mm}$ on yearly basis. It was also observed that rainfall is becoming increasingly unpredictable with poor distributions throughout the season. Results from the linear and non-linear regression models suggest that rainfall increase and crop area expansion have a positive and significant influence on mean maize yield. However, temperature increase will adversely affect mean maize yield. In conclusion, the study found that there exists not only a linear but also a non-linear relationship between climatic variables and maize yield.
\end{abstract}

Keywords: Climatic variables, crop area, maize yield, regression model, model selection

\section{Introduction}

Climate change poses a significant threat to Sub-Saharan Africa's (SSA) Agriculture, especially so in Ghana where agricultural production depends mainly on natural conditions. This exposes the agricultural sector to the effects of present climate variability and the risks of future climate change. In general, temperature increase will reduce yields and quality of food-crops thereby worsening vulnerability in food supply. Similarly, changes in precipitation patterns i.e., intensive rain concentrated in a particular month has a devastating effect on crop production (Abrol \& Ingram, 1996). This threatens the achievement of Millennium Development Goals aimed at poverty and hunger reduction, health improvement and environmental sustainability (United Nations Development Programme UNDP, 2010). Numerous empirical studies on climate change impacts on agriculture suggest that the effects of climate change will not be uniform across the globe. According to these studies, developed countries will be less affected by climate change compared to developing countries. Notwithstanding, there are very limited researches in developing countries on what will be the impacts of climate change on the agricultural sector. Therefore, the impact of climate change on the agricultural sector is of paramount concern, particularly in the low-income countries where majority of the people are living in rural areas. However, crop growth is not only affected by climatic factors but also nonclimatic factors such as crop area. For instance, in Sub-Saharan Africa area expansion contributes significantly to the growth of agricultural production. Maize is one of the staples of Ghana and it is cultivated on more than, 991,661 hectares and across all agro ecological regions in Ghana (Statistics, Research and Information Directorate SRID, 2010). The crop constitutes a rich source of carbohydrate for both human and animal's nutrition. It also contributes over $20 \%$ of the incomes earned by small-scale farmers in Ghana. The critical importance of maize to food self-sufficiency and food security in Ghana is reflected in the establishment of the Ghana Grains Development Project (GGDP) in 1979 - a joint venture between the government of Ghana and Canada. Although maize plays a significant role in the Ghanaian economy, the impact of climatic variables and crop area on its yield has not been extensively investigated in Ghana. The fundamental problem is that the relationship between climatic variables, cultivated area and maize yield is not clearly understood. The issue of whether a linear or non-linear relationship is the most appropriate to describe the relationship between variables remain unanswered. However, understanding the relationship between the climatic variables, cultivated area and maize yield will facilitate preparation of appropriate 
policies and adaptation mechanisms within the maize production sector. In addition, it will add to the growing body of knowledge on climate change and maize production, specifically in the Ghanaian context. Against this background, we empirically estimate the effect of climatic variables and crop area on maize yield.

\section{Literature Review}

Ghana is located in West Africa on the Guinea Coast and has a tropical climate. Agriculture and livestock constitute the mainstay of Ghana's economy, accounting for 32\% of GDP in 2009 and employing 55\% of the economically active population (World Bank, 2009). Agriculture is predominantly rain fed, which exposes it to the effects of present climate variability and the risks of future climate change. Rainfall over Ghana was particularly high in the 1960s, and decreased to particularly low levels in the late 1970s and early 1980s, producing an overall decreasing trend in the period 1960 to 2006, with an average precipitation of $2.3 \mathrm{~mm}$ per month $(2.4 \%)$ per decade (National Development Planning Commission [NDPC] \& United Nations Development Programme [UNDP], 2010). Temperature data since 1960 indicates that mean annual temperature has increased by $1.0^{\circ} \mathrm{C}$, at an average rate of $0.21^{\circ} \mathrm{C}$ per decade. The rate of increase has been higher in the northern regions of the country than in the south (NDPC \& UNDP, 2010). Different methods exist to assess the effect of climate change on crop yields. The two main methods used are: 1) Crop Growth Models and 2) Regression Analysis (Blanc, 2011). Crop growth models among which include AGROSIM (an acronym of AGRO-ecosystem Simulation) and CropSyst (Cropping Systems Simulation Model) are able to capture the effect of weather and its variability since they use daily climatic data (Sonka \& Lamb, 1987). Using a crop growth model, Chipanshi et al., (2003) investigated the effects of climate change on maize yields in Botswana and predicts that simulated maize yields are expected to decrease up to $10.3 \%$. However, crop growth models cannot be applied to wide areas because of the limitation imposed by the need for daily weather data (Blanc, 2011). Alternatively, regression analyses allow the quantification of weather changes on crop yields in an actual cropping context (Blanc, 2011). Joshi et al. (2011) employed a regression model to investigate the effect of climatic variables on yield of major food-crops in Nepal using historical data. The authors found that increase in summer rain and maximum temperature has contributed positively to rice yield. In addition, increase in summer rain and minimum temperature has positive impact on potato yield. However, increase in summer rain and maximum temperature adversely affected the yield of maize and millet. Lobell and Field (2007) conducted a study on maize at the world level and found that on a yearly basis, the weather for the period 1961-2002 is responsible for 47\% change in maize yields. In addition, Lobell and Asner (2003) estimated a $17 \%$ decrease in maize yields for the period $1982-1998$ due to a $1^{\circ} \mathrm{C}$ rise in temperature during the growing season.

\section{Methodology}

Desk research was used to obtain secondary data from the Statistical, Research and Information Directorate (SRID) of the Ministry of Food and Agriculture (MoFA) and the Metrological Services Department of Ghana. The use of secondary data is essential to adequately capture past weather patterns and their effect on maize production in the study area. Observed average national maize yields and the corresponding cultivated area are used for the study. In addition, observed average growing season rainfall and temperature values is used. The data set was available over time for the period 1970 to 2010. This study employs two-model specifications (linear and non-linear) relating maize yield to crop area and climatic variables. The general form of the models is specified as;

$$
\Delta \text { Yield }=\Delta \text { Crop area }+ \text { Rain }+ \text { Tempt }+\varepsilon
$$

Where $\Delta$ Yield is the observed change in maize yield, $\Delta$ Crop area is observed change in the corresponding crop area, Rain and Tempt are the observed rainfall and temperature values for the growing season, and $\varepsilon$ is the residual term. The agronomic variables (maize yield and crop area) are logged to improve their distributions but the climatic variables are not in order to produce semi-elasticities. Some factors are not considered in the model because of technical difficulties and data limitations. For instance, the correlation between solar radiation and temperature makes it difficult to examine the specific effect of sunlight on crop yield (Evans, 1996). Additionally, the effect of rainfall would be better represented by rainfall distribution (Meng \& Quiring, 2010), but it is not possible to include this variable due to data limitations. A time series analysis is 
used since the data set was available over time. The presence of unit root is tested using the unit root test proposed by Elliott-Rothenberg- Stock (ERS) (Elliott et al., 1996). This test is preferred because of its greater power and because it performs better with small samples. The ERS test has a null hypothesis of a unit root and an alternative hypothesis of stationary. The maximum lag length was first chosen according to the proposal of Schwert (1989). To select the model that bests fit the dataset, this study uses information criteria as technique for providing the basis for model selection. There exist a number of information criteria's but the most widely and commonly used ones are the Akaike Information Criteria (AIC) and Schwarz Bayesian Information Criteria (SBIC). The idea of both AIC and SBIC is to select a model that minimizes the negative likelihood penalized by the number of parameters. AIC is specified as:

$$
\text { AIC }=-2 \log (\mathrm{L})+2 \mathrm{k}
$$

Where, $L$ refers to the maximum value of the likelihood function under the fitted model and $k$ is the number of parameters in the model.

In addition, SBIC is specified as

$$
\mathrm{SBIC}=-2 \log (\mathrm{L})+\mathrm{k} \log (\mathrm{N})
$$

Where $L$ refers to the maximum value of the likelihood function under the fitted model, $\mathrm{k}$ is the number of parameters in the model and $\mathrm{N}$ is the number of observations or sample. The only deference between AIC and SBIC is that the latter tends to have greater penalty for the number of parameters in the model than the former. All analysis is implemented using Stata 11 and Eviews 5.0.

\section{Results and Discussion}

Trend of Climatic Variables: Climatic variable trends are analysed on a seasonal basis to coincide with the growing season of maize both in the northern and southern zones of Ghana. Average temperature and rainfall values for the effective growing season were obtained from ten synoptic stations representing the ten regions in Ghana. The results of the climatic variables trend against time indicate that growing seasonal temperature is increasing significantly by $0.03^{\circ} \mathrm{C}$ over the study period $(1970-2010)$. Rainfall fluctuates over the years with less degree of predictability. However, growing seasonal rainfall trend was found to be increasing insignificantly by $0.25 \mathrm{~mm}$ over the same period. These findings are consistent with the findings of Environmental Protection Agency (2000) and Minia (2004). Both studies found that climate change impact assessment in Ghana showed trends towards rising temperatures and declining rainfall for all ecological zones.

\section{Figure 1: Trend of average growing seasonal temperature}

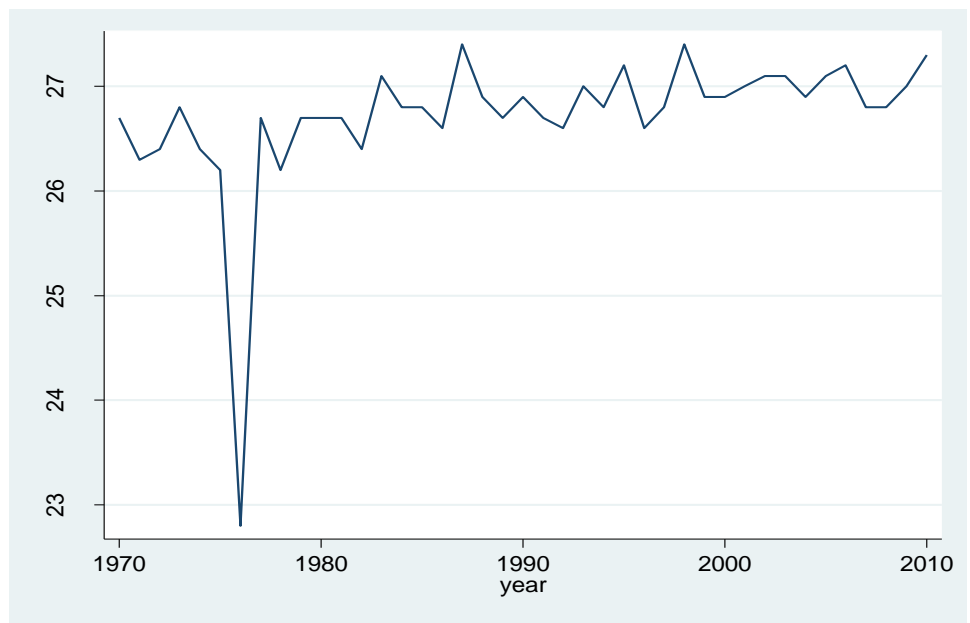

Source: Meteorological Services of Ghana 
Figure 2: Trend of average growing seasonal rainfall

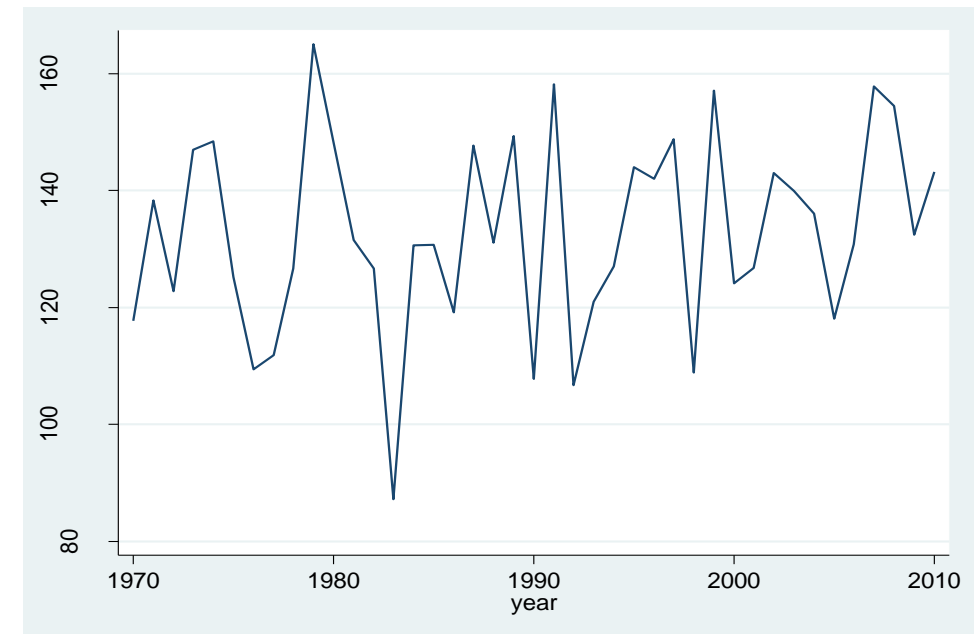

Source: Meteorological Services of Ghana

Effect of Climatic Variables and Crop Area on Maize Yield: ERS unit root test was conducted to examine the time series properties of the variables of study. The null hypothesis of a unit root is rejected for the climatic variables and the first-differenced agronomic (maize yield and crop area) variables. Table 1 and Table 2 displays the results of the unit root tests for the agronomic and climatic variables respectively.

Table 1: ERS unit root test (with constant and trend) for agronomic variables

\begin{tabular}{lllll}
\hline Variable & Level & Critical value & First difference & Critical value \\
\hline Yield & $-1.236(3)$ & -3.166 & $-3.606(3)$ & $-3.170^{*}$ \\
Crop area & $-1.949(3)$ & -3.166 & $-3.467(3)$ & $-3.170^{*}$ \\
\hline
\end{tabular}

Notes: values in parenthesis indicate the optimum lag length based on SBIC; "*" denote significance at the $5 \%$.

Table 2: ERS unit root test (with constant and trend) for climatic variables

\begin{tabular}{lll}
\hline Variable & Level & Critical value \\
\hline Rainfall & $-4.679(3)$ & $-3.166^{*}$ \\
Temperature & $-2.741(3)$ & $-3.166^{*}$ \\
\hline
\end{tabular}

Notes: values in parenthesis indicate the optimum lag length based on SBIC; "*" denote significance at the 5\%.

Table 3 displays the marginal impacts of climatic variables and crop area on maize yield. The results suggest that the model is able to describe $80 \%$ of the variations in the yield of maize in Mt/Ha. The F-statistics implies the function to be well behaved. The findings of the linear model show that growing season rainfall and crop area has a positive and significant impact on maize yields. This means that a percentage change in crop area is expected to increase maize yields by $1.2 \%$ and a $10 \mathrm{~mm}$ increase in rainfall during the growing season is expected to increase maize yields by $0.36 \%$. Maize yield is expected to decrease by $2.7 \%$ with a $1^{\circ} \mathrm{C}$ rise in temperature during the growing season though not significant. This result is consistent with the finding of You et al. (2009). The authors when focusing on China from 1979 - 2000 found wheat yields to decrease by $0.5 \%$ because of $1 \%$ rise in growing season temperature. With precipitation, the authors found a positive impact though smaller. Similarly, in a study conducted on maize at the world level from the period 1961 2002, Lobell \& Field (2007) found that maize yields decreased by $17 \%$ with a $1{ }^{\circ} \mathrm{C}$ rise in growing season temperature.

\section{Linear model specification}

$\log ($ yield $)=\beta_{0}+\beta_{1}(\log$ crop area $)+\beta_{2}$ temperature $+\beta_{3}$ rainfall $+\varepsilon$ 
Table 3: Parameter estimates for linear model

\begin{tabular}{lll}
\hline Response variable: $\log$ (yield) in Mt/Ha & & \\
\hline Control Variable & Coefficient & P-value \\
\hline Intercept & $0.231(0.891)$ & 0.797 \\
Log (crop area) & $1.201(0.111)$ & $0.000^{*}$ \\
Temperature & $-0.027(0.034)$ & 0.434 \\
Rainfall & $0.0036(0.0014)$ & $0.012^{*}$ \\
$\mathrm{R}^{2}$ & 0.80 & \\
F statistic & 48.11 & $0.000^{*}$ \\
\hline
\end{tabular}

Number of observation: 40

Notes: standard errors in parentheses; ${ }^{*}$ denotes significance at $1 \%$ level.

Table 4 displays the regression results of the non-linear model specification. The specification is meant to account for non-linear weather effect on maize yield (Katz, 1977). The model explains about $80 \%$ of the variations in maize yields and the F-statistic show the function to be well behaved. The findings indicate that rainfall and crop area has a positive and significant effect on maize yield. This means that increasing rainfall during the growing season is expected to increase maize yields. However, increasing temperature during the growing season is expected to cause decline in maize yield. The result of the non-linear model specification implies there exist not only a linear but also a non-linear relationship between maize yield, crop area and climatic variables. This result tends to agree with the findings of Malone et al. (2009). The authors specified a model that included a temperature squared term and found a concave relationship between maize yields and early season maximum temperature and a convex relationship between yield and late season maximum temperature.

Non-linear model specification

$\log ($ yield $)=\beta_{0}+\beta_{1}(\log$ crop area $)+\beta_{2}(\text { temperature })^{1 / 2}+\beta_{3}(\text { rainfall })^{1 / 2}+\varepsilon$

Table 4: Parameter estimates for non-linear model

\begin{tabular}{lll}
\hline Response variable: $\log$ (yield) in Mt/Ha & & \\
\hline Control Variable & Coefficient & P-value \\
\hline Intercept & $0.231(0.891)$ & 0.797 \\
Log (crop area) & $1.201(0.111)$ & $0.000^{*}$ \\
(Temperature) $^{1 / 2}$ & $-0.053(0.067)$ & 0.434 \\
Rainfall) $^{1 / 2}$ & $0.007(0.003)$ & $0.012^{*}$ \\
$\mathrm{R}^{2}$ & 0.80 & \\
F statistic & 48.11 & $0.000^{*}$ \\
\hline
\end{tabular}

Number of observation: 40

Notes: standard errors in parentheses; * denotes significance at $1 \%$ level.

Model Comparison based on information criteria, estimated competing models are compared. Table 5 displays the values of both AIC and SBIC for the estimated models.

Table 5: AIC and SBIC values for estimated models

\begin{tabular}{lll}
\hline Model & AIC & Ranking \\
\hline Linear & -0.961 & 1 \\
Non linear & -0.961 & 1 \\
\hline
\end{tabular}


The values for AIC and SBIC in the linear and non-linear models are equal and equivalent to $\quad-0.961$ and 0.792 for AIC and SBIC respectively. These results suggest that the ability of the linear and non-linear models in explaining the data generating process (maize yield) is the same.

\section{Conclusion}

This study sought to empirically understand the effect of climatic variables and crop area on maize production in Ghana. The results reveal that growing season temperature is significantly increasing and growing season rainfall is increasingly becoming unpredictable. There is a positive and significant relationship between rainfall, crop area and maize yield. In general, temperature increases during the growing season will adversely affect maize yield. More so, the relationship between climatic variables and maize yield is found not to be only linear but also non-linear. The study recommends that major stakeholders should raise awareness and educate farmers on the significant increases in temperature and the need to adapt to the increasing temperature. Furthermore, the relationship between crop yield and climatic variables in Ghana should be analysed using both linear and non-linear models. This is because; the competing models lead to similar conclusions. Future research will consider the use of other estimation techniques in analyzing the effect of climatic variables and crop area on maize yield.

\section{References}

Abrol, Y. P. \& Ingram, K. T. (1996). Effects of higher day and night temperatures on growth and yields of some crop plants. In F. Bazzaz, \& W. Sombroek Ed: Global climate change and agricultural production: Direct and indirect effects of changing hydrological, pedological and plant physiological processes. John Wiley \& Sons Ltd, West Sussex, England. 123-140.

Blanc, E. (2011). The impact of climate change on crop production in Sub-Saharan Africa. Unpublished Doctor of Philosophy thesis, University of Otago, Dunedin, New Zealand.

Chipanshi, A. C., Chanda, R. \& Totolo, O. (2003). Vulnerability assessment of the maize and Sorghum crops to climate change in Botswana. Climatic Change, 61(3), 339-360.

Elliott, G., Rothenberg, T. \& Stock, J. H. (1996). Efficient tests for an autoregressive unit root. Econometrica, 64(4), 813-836.

Evans, L. T. (1996). Crop evolution, adaptation and yield. Cambridge, Cambridge University press.

Joshi, N. P., Maharjan, K. L. \& Piya, L. (2011). Effect of climate variables on yields of major food-crops in Nepal - A Time-series Analysis. Journal of Contemporary India Studies: Space and Society, Hiroshima University, 1, 19-26.

Katz, J. J. (1977). Propositional structure and illocutionary force: A study of the contribution of sentence meaning to speech acts. New York: T. Y. Crowell.

Lobell, D. \& Field, C. (2007). Global scale climate-crop yield relationships and the impacts of recent warming. Environmental Research Letter 2.

Lobell, D. B. \& Asner, G. P. (2003). Climate and management contributions to recent trends in U.S. agricultural yields. Science, 299(5609), 1032.

Malone, C. D., Brennecke, J., Dus, M., Stark, A., McCombie, W. R., Sachidanandam, R. \& Hannon, G. J. (2009). Specialized piRNA pathways act in germline and somatic tissues of the Drosophila ovary. Cell, 137(3), 522--535.

Meng, L. \& Quiring, S. M. (2010). Examining the influence of spring soil moisture anomalies on summer precipitation in the U.S. Great Plains using the Community Atmosphere Model version 3. J. Geophys. Res., 115, D21118, doi:10.1029/2010JD014449.

Schwert, G. W. (1989). Tests for Unit Roots: A Monte Carlo investigation. Journal of Business and Economic Statistics, 7, 147-160.

Sonka, S. T. \& Lamb, P. J. (1987). On Climate change and economic analysis. Climatic Change, 11(3), 291- 311.

UNDP. (2010). Climate change and the millennium development goals. http://www.undp.org/climatechange/cc_mdgs.shtml.

United Nations Development Programme. (2010). Beyond the midpoint: Achieving the Millennium Development Goals. New York. 
World Bank. (2009). Swimming against the tide: How developing countries are coping with the global crisis. Washington, DC.

World Bank. (2003). Africa rainfall and temperature evaluation system (ARTES). Washington, D.C.

\section{APPENDIX}

Figure A: Graphical presentation of the Unit root test for maize yield at level and first difference.
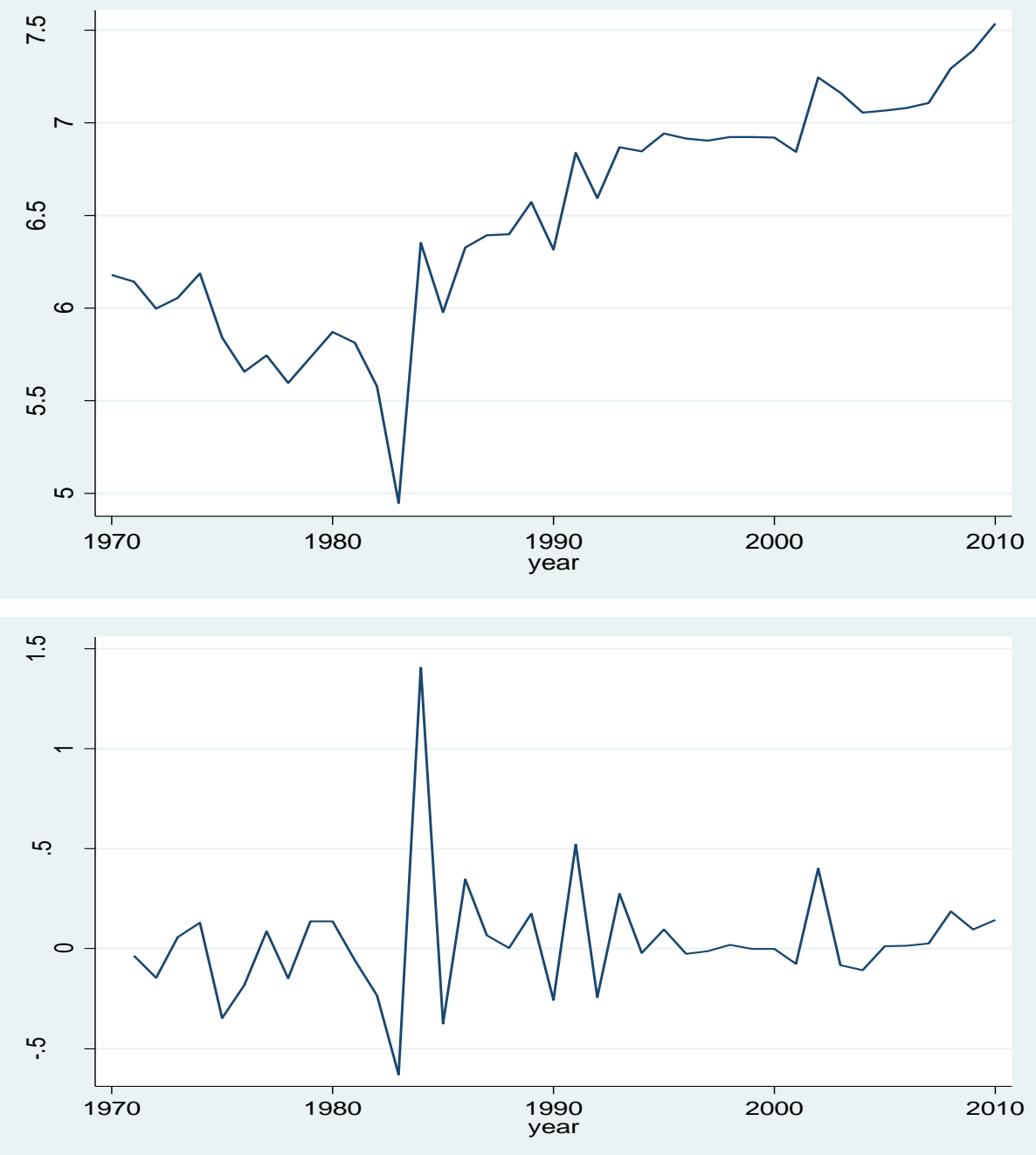
Figure B: Graphical presentation of the Unit root test for crop area at level and first difference.
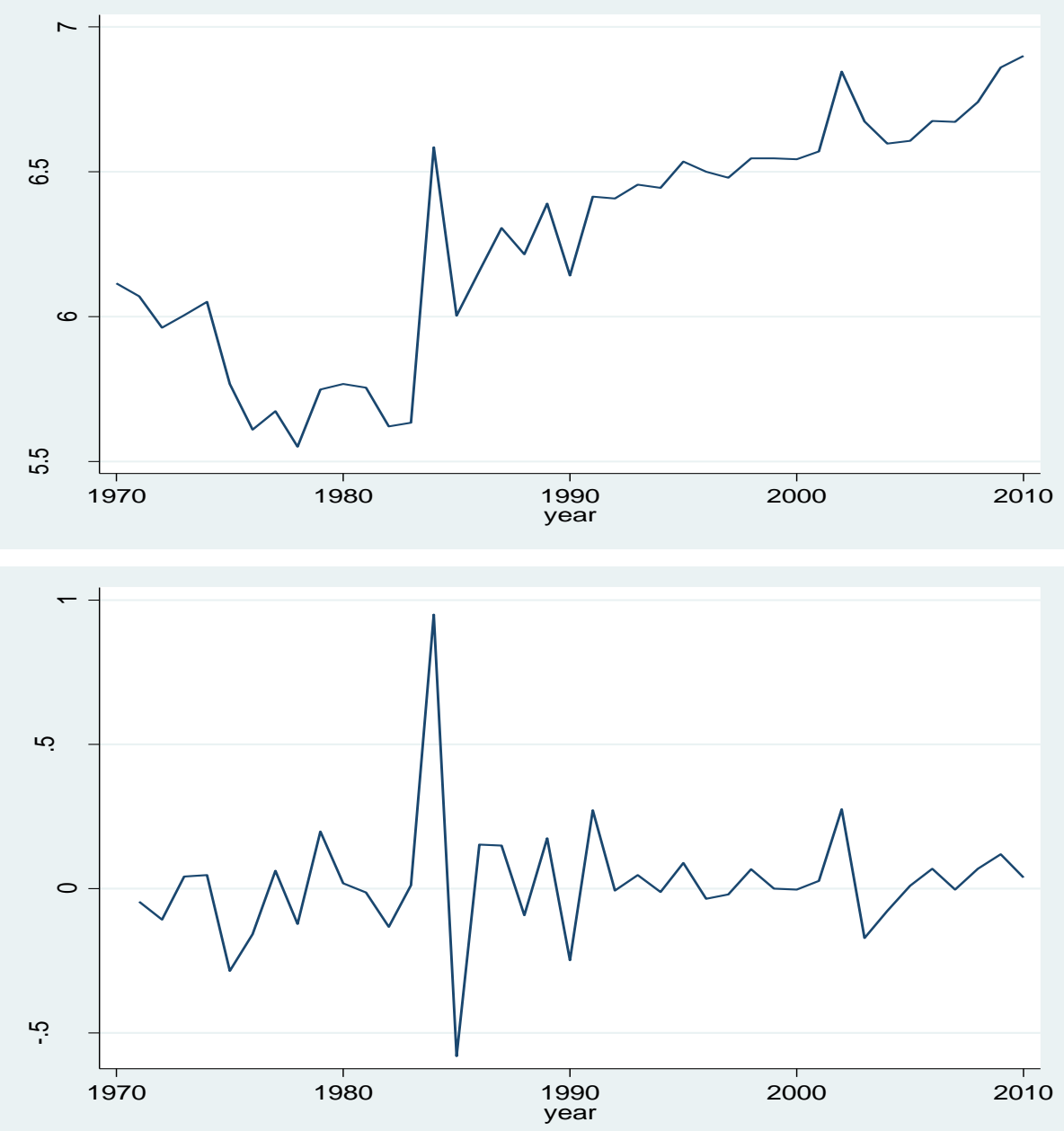
Figure C: Graphical presentation of the Unit root test for rainfall at level

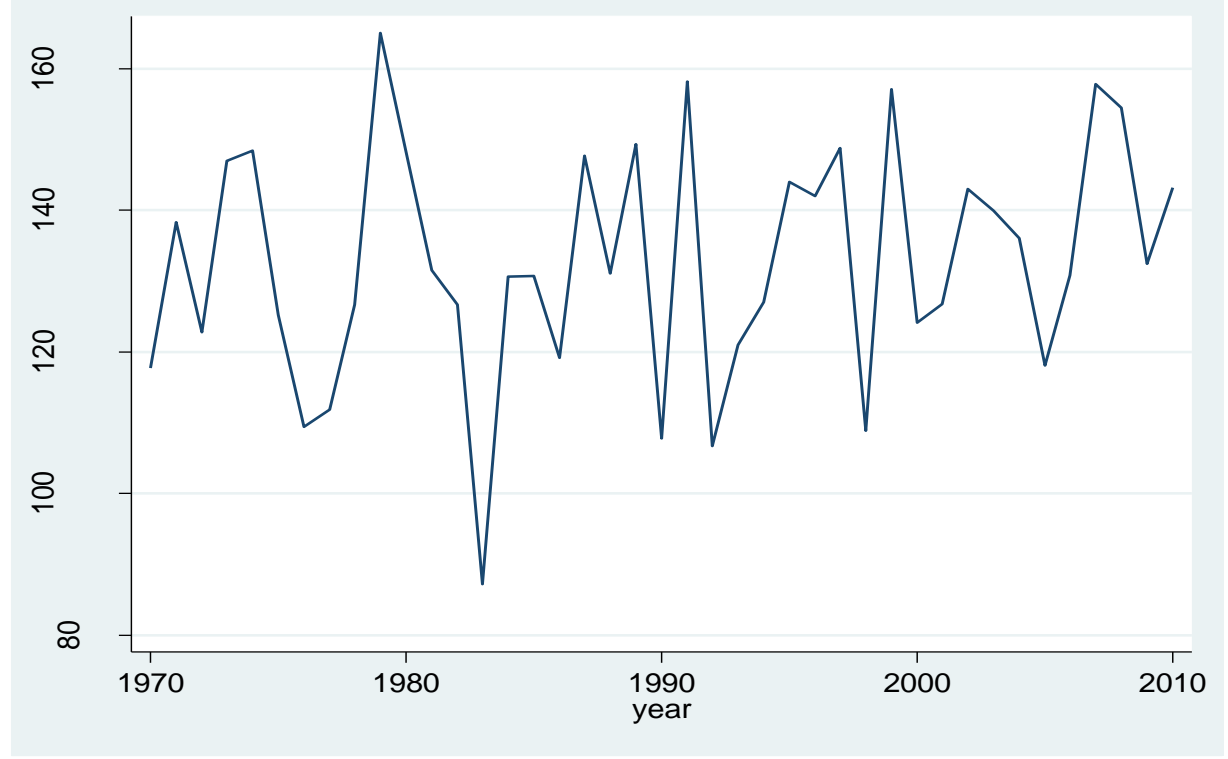

Figure D: Graphical presentation of the Unit root test for temperature at level

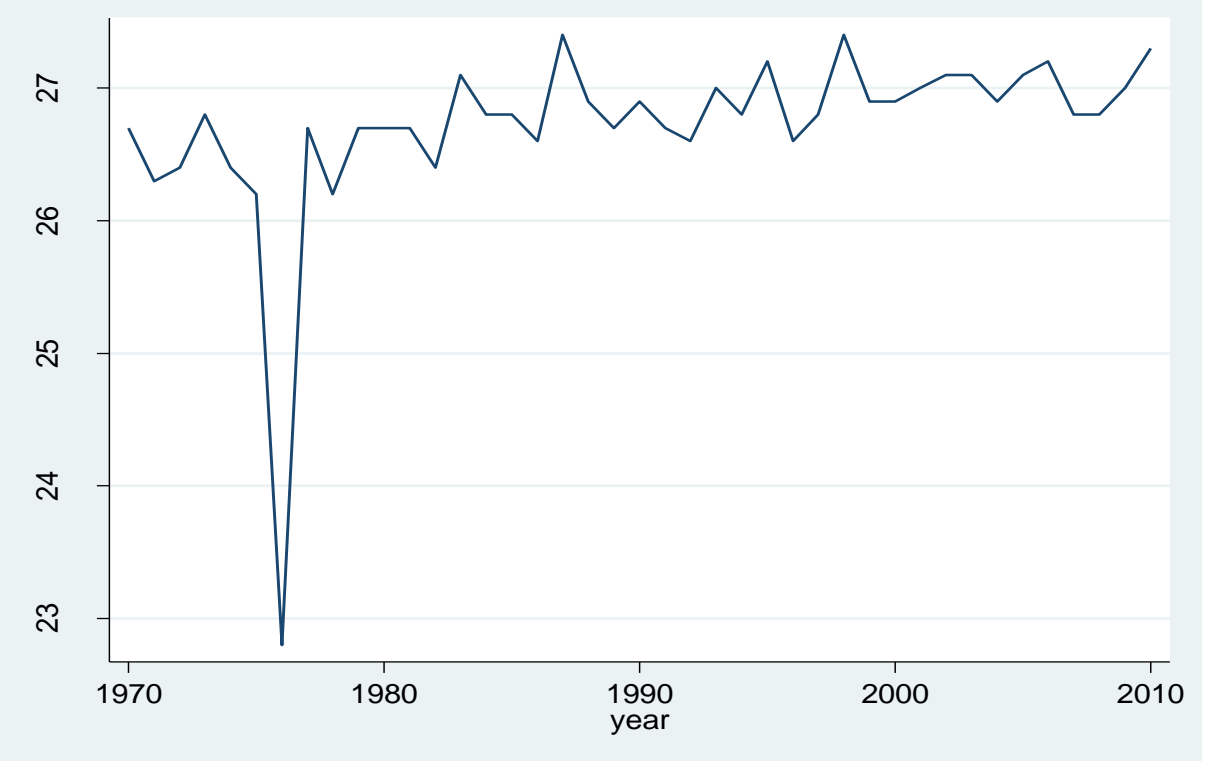

